\title{
Musical practice and cognitive aging: two cross-sectional studies point to phonemic fluency as a potential candidate for a use-dependent adaptation
}

\section{Baptiste Fauvel 1,2,3,4, Mathilde Groussard ${ }^{1,2,3,4}$, Justine Mutlu ${ }^{1,2,3,4}$, Eider M. Arenaza-Urquijo ${ }^{1,2,3,4}$, Francis Eustache ${ }^{1,2,3,4}$, Béatrice Desgranges ${ }^{1,2,3,4}$ and Hervé Platel ${ }^{1,2,3,4 *}$}

${ }^{1}$ Institut National de la Santé et de la Recherche Médicale, U1077, Caen, France

2 Université de Caen Basse-Normandie, Unité Mixte de Recherche-S1077, Caen, France

${ }^{3}$ Ecole Pratique des Hautes Études, Unité Mixte de Recherche-S1077, Caen, France

${ }^{4}$ Centre Hospitalier Universitaire de Caen, U1077, Caen, France

Edited by:

P. Hemachandra Reddy, Oregen

Health and Science University, USA

Reviewed by:

E. Glenn Schellenberg, University of

Toronto, Canada

Brenda Hanna-Pladdy, University of

Maryland School of Medicine, USA

${ }^{*}$ Correspondence:

Hervé Platel, Institut National de la

Santé et de la Recherche Médicale -

Ecole Pratique des Hautes

Études-Université de Caen

Basse-Normandie, Unité U1077,

U.F.R. de Psychologie, Université de

Caen Basse-Normandie, Esplanade

de la Paix, 14032 Caen Cedex,

France

e-mail: herve.platel@unicaen.fr
Because of permanent use-dependent brain plasticity, all lifelong individuals' experiences are believed to influence the cognitive aging quality. In older individuals, both former and current musical practices have been associated with better verbal skills, visual memory, processing speed, and planning function. This work sought for an interaction between musical practice and cognitive aging by comparing musician and non-musician individuals for two lifetime periods (middle and late adulthood). Long-term memory, auditory-verbal short-term memory, processing speed, non-verbal reasoning, and verbal fluencies were assessed. In Study 1, measures of processing speed and auditory-verbal short-term memory were significantly better performed by musicians compared with controls, but both groups displayed the same age-related differences. For verbal fluencies, musicians scored higher than controls and displayed different age effects. In Study 2, we found that lifetime period at training onset (childhood vs. adulthood) was associated with phonemic, but not semantic, fluency performances (musicians who had started to practice in adulthood did not perform better on phonemic fluency than non-musicians). Current frequency of training did not account for musicians' scores on either of these two measures. These patterns of results are discussed by setting the hypothesis of a transformative effect of musical practice against a non-causal explanation.

Keywords: cognitive aging, brain reserve, musical practice, cognitive transfer, verbal functions

\section{INTRODUCTION}

Normal brain and cognitive aging are challenging to study, as advancing age is often associated with various pathologies that compromise cognition. However, there are accumulating evidences suggesting that, even in pathology-free conditions, normal aging is associated with changes in the neural basis of cognition (Hedden and Gabrieli, 2004; Kalpouzos et al., 2009). Cognitive functions are disproportionally impacted by aging, the earliest and most concerned are processing speed, working memory, spatial ability, reasoning, and long-term memory (Hedden and Gabrieli, 2004; Salthouse, 2010). By contrast, measures of semantic knowledge and verbal abilities are relatively stable across the lifespan (Park et al., 2002).

Studies have reported that the brain retains its dynamic properties in aging, with structural and functional rearrangements allowing for new learning and skills improvements (Draganski and May, 2008). It has been suggested that all lifelong environmental features and demands contribute to the establishment of a cognitive reserve, thereby partly counteracting the agerelated cognitive decline (Foubert-Samier et al., 2010). Therefore, besides genetic dispositions, both former and current individuals' experiences may influence the quality of cognitive aging (Hultsch et al., 1999; Wilson et al., 2005; Stern, 2012), raising hopes for therapeutic interventions and/or daily lifestyle recommendations (Green and Bavelier, 2008). Epidemiological works have shown that, in addition to education (Evans et al., 1993) and occupational activity (Adam et al., 2013), the degree of individuals' engagement in leisure activities covaries with cognitive functioning in old age (Wang et al., 2012). For instance, Christensen and Mackinnon (1993) found a positive statistical link between mental, social, and physical activities and the cognitive performances of a large sample of participants aged 70-89 years. Longitudinal studies have confirmed that practicing leisure activities in later life is linked to increases in cognitive reserve (Schooler and Mulatu, 2001).

Regarding musical practice, cross-sectional works in children and young adults have reported an association with better performances across a wide range of cognitive domains. Individuals who practice music in their spare time have been found to significantly outperform matched non-musicians on verbal memory (Chan et al., 1998; Brandler and Rammsayer, 2003; Ho et al., 2003; Franklin et al., 2008; Jakobson et al., 2008), vocabulary 
(Forgeard et al., 2008), spatial ability (Brochard et al., 2004), non-verbal reasoning (Forgeard et al., 2008), short-term memory (Huntsinger and Jose, 1991; Tierney et al., 2008), and working memory (Franklin et al., 2008).

It has been hypothesized that music training has transformative effects on specific cognitive functions because they share mechanisms (e.g., auditory processes involved both in music and in language; Patel and Iversen, 2007; Fauvel et al., 2013; Dawson, 2014). Another claim is that music lessons, being scholar-like activities, instead of leading to specific cognitive improvements, result in a small general gain in Intelligent Quotient (IQ; Schellenberg, 2004), possibly through the potentiation of executive functions (Hannon and Trainor, 2007; Schellenberg and Peretz, 2008; but see Schellenberg, 2011).

However, environmental factors influencing human cognition are challenging to study as well, and previous positive results from quasi-experimental studies should be interpreted with caution regarding the direction of the causality (e.g., high-functioning people are more likely to take music lessons; Schellenberg, 2011). Moreover, a recent well-controlled (random assignment) longitudinal study observed that visual art or music preschool instruction did not influence children's cognitive development (Mehr et al., 2013).

In seeking for potential factors that could promote successful cognitive aging, cross-sectional studies have revealed that both past and recent musical training are associated with better cognitive performances in later life (Hanna-Pladdy and MacKay, 2011; Hanna-Pladdy and Gajewski, 2012). A study conducted in older musicians (60-83 years) with two levels of expertise (high activity ( $>10$ years) vs. low activity ( $<10$ years) found that they scored higher than non-musicians on the delayed recall of a geometric shape (visual long-term memory), a verbal naming task, and Parts A and B of the Trail Making Test (TMT A and B), which measures processing speed (Hanna-Pladdy and MacKay, 2011). Although the performances of the low-activity musicians were halfway between those of the controls and high-activity musicians, suggesting a causal explanation, the differences were not significant. Moreover, those musicians who were still actively engaged in music at the time of the study did not perform better than those who had ceased.

In another study (Hanna-Pladdy and Gajewski, 2012) where general lifestyle activities were controlled for, findings were replicated for visuospatial judgment, verbal memory, verbal working memory, planning functions (non-musicians made more rule violations in an executive function-related task), and phonemic fluency. Statistical analyses revealed that the musicians' visuospatial ability was predicted by recent musical engagement, whereas auditory-verbal memory seemed to be influenced by the early age of musical acquisition. The authors suggested that it could reflect differences in use-dependent adaptation periods depending on cognitive domain.

\section{ISSUES}

In their investigation of the association between musical practice and late-life cognition, already published works have focused on musicians who started their training around 10 years old, while quasi-experimentally manipulating the current engagement (active vs. inactive), and by implication, the total duration of training (more or less than 10 years; Hanna-Pladdy and MacKay, 2011; Hanna-Pladdy and Gajewski, 2012). Therefore, the question of whether old musicians who started practicing music in adulthood also display better cognitive performances remains unanswered.

Moreover, any differences uncovered by comparing musicians and non-musicians at a single point in time are of a quantitative nature, and do not inform about the cognitive aging quality of these two populations (i.e., is musical practice associated with better performances in old age and weaker cognitive decline).

The first aim of the present work was to confirm that individuals practicing music since childhood display better cognitive performances than non-musicians. Then, we wanted to explore whether these two populations differ in terms of aging-related performances evolution. Finally, we looked at whether two different characteristics of practice (age at training onset and current frequency of training) account for older musicians.

Indeed, in the perspective that musical training influences the aging of cognitive abilities by stimulating them, we hypothesized that:

(i) Some tests' results would be higher in musically-trained participants and display weaker age-related differences between middle-aged and older participants compared with non-musicians.

(ii) For cognitive functions displaying this pattern, at least one of the two characteristics of musical practice (age at onset and/or current frequency of training) would be associated with the musicians' performances.

Therefore, in Study 1, we assessed several cognitive functions in middle-aged and older musicians (all having started in childhood), and compared their cognitive performances, together with the age-dependent differences, with those of middle-aged and older non-musicians (cf. Figure 1).

In Study 2, we wanted to explore whether two variables of practice (i.e., lifetime period at training onset and current frequency of training) could explain the older musicians' higher scores. We therefore included a sample of older individuals who had started music later in life (mean age at training onset $=42.7$ years, $S D=11$ ), and measured their cognitive performances on tests having revealed significant interactions in Study 1. In addition, we ran a correlation analysis between these test scores and all the older musicians' current frequency of training.

\section{STUDY 1: MATERIALS AND METHODS PARTICIPANTS}

This study was made according to the ethical recommendations of Helsinki agreements for human researches and cognitive investigations. Sixty-eight individuals were included. All were informed about the study's details and gave their consent for participation.

Thirty-four were amateur musicians recruited from several French conservatories or music schools (no self-educated musicians were included). They were required to have an uninterrupted time of practice of at least 4 years at the time of the study, and for a frequency of training of more than $2 \mathrm{~h}$ a week during 
the last 6 months. To make sure that the musicians had an "active" practice, rather than a routinized one, a further inclusion requirement was that they had to have learned at least two new music pieces in the course of the previous year. They played various musical instruments (piano, guitar, trumpet, etc.). Overall, the mean training duration was 38.12 years $(S D=17.7)$, with a mean age at training onset of 9.54 years $(S D=4.14)$, and a frequency of current training of $12.6 \mathrm{~h}$ per week $(S D=10.7)$ (cf. Table 1$)$. This sample was divided into a middle-aged group (19 participants, mean age $=40.7$ years, $S D=9.6, \min =21, \max =55)$ and an

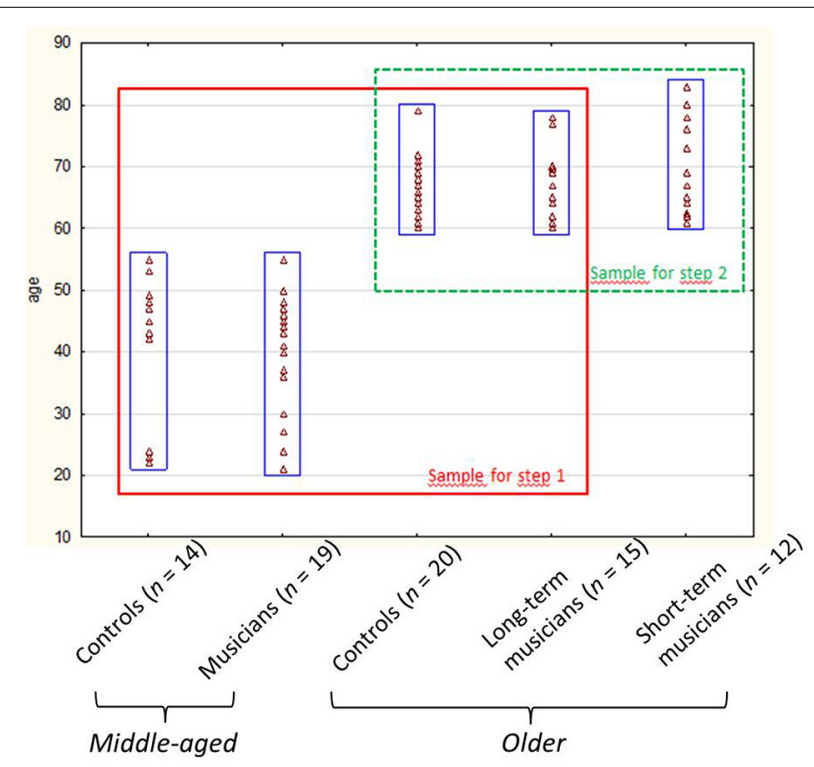

FIGURE 1 | Dispersion graph showing the participants' ages in Study 1 (red square) and 2 (green square). older group (15 participants, mean age $=67.1$ years, $S D=5.2$, $\min =60, \max =78)$.

The 34 control participants were recruited from the general population. This sample was also divided into a middle-aged group (14 participants, mean age $=38.86$ years, $S D=15.9$, $\min =22, \max =55)$ and an older group (20 participants, mean age $=67$ years, $S D=4.4, \min =60, \max =79)($ cf. Table 1$)$.

The cut-off ages (middle-aged $\leq 55-60 \leq$ older) were chosen because of works showing that cognitive performances fall significantly below the mean of the general population at around this age (Salthouse, 2010).

All participants were given a semi-structured questionnaire that had been specially designed for the study in order to rate demographic data (gender, age, education, and occupation) (cf. Table 1). The stimulating quality of the participants' occupations was rated as follows: a value of 1 was attributed for jobless individuals; 2 for manual workers; 3 for office workers, public-sector workers, tradespeople, and storekeepers; 4 for the self-employed, executive managers, and students; and 5 for physicians and company directors. The musicians were also asked to evaluate their age at training onset, and its average frequency for the last 6 months. Based on this questionnaire, the groups of participants were matched on gender, age, education, and occupational level. Moreover, middle-aged and older musician groups differed only marginally on age at training onset as well as frequency of practice (cf. Table 1).

\section{NEUROPSYCHOLOGICAL ASSESSMENT}

The neuropsychological assessment was made of 8 tests that are classically used in a clinical context (cf. Table 2). The entire test battery was administered in a single session which lasted about $90 \mathrm{~min}$, and took place in a quiet room conducive to concentration. As the whole recruitment extended through 3 years and was shared between master's degree students in psychology, eight different experimenters were trained to run the tests in the most

Table 1 | Means (SDs) and inferential statistics for demographic data and characteristics of musical practice (trend/significance $p$-values: $\$ p \leq 0.1$.

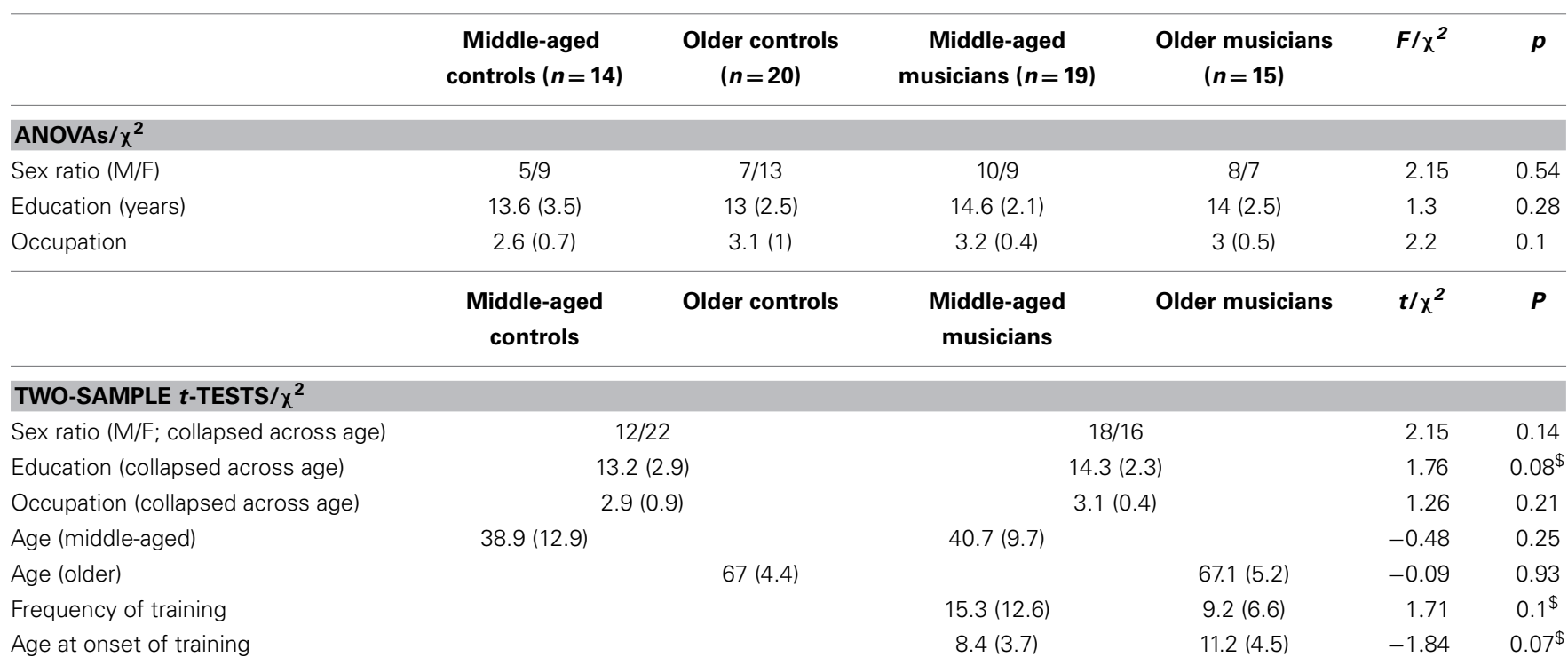


Table 2 | List of the tests used, the cognitive functions they assess, and the scores retained.

\begin{tabular}{|c|c|c|}
\hline Psychometric tests & Dependent variables (outcomes) & Cognitive functions assessed \\
\hline $\begin{array}{l}\text { Delayed recall of the Signoret BEM-144's } 12 \text { words } \\
\text { (Signoret, 1991) }\end{array}$ & Number of words recalled. & Verbal long-term memory, free recall. \\
\hline $\begin{array}{l}\text { Delayed recall of Rey-Osterrieth complex figure } \\
\text { (Rey, 1959) }\end{array}$ & $\begin{array}{l}\text { Recall fidelity (number of details, their completeness, } \\
\text { and location). }\end{array}$ & Visual long-term memory, free recall. \\
\hline Forward digit span (Godefroy et al., 2008) & Highest number of digits properly recalled in $2 / 3$ trials. & Auditory-verbal short-term memory. \\
\hline d2 test (Brickenkamp, 1981) & Sum of the number of items processed per line in $15 \mathrm{~s}$. & Processing speed, visual discrimination. \\
\hline $\begin{array}{l}\text { Semantic and phonemic fluency tasks (Cardebat } \\
\text { et al., 1990) }\end{array}$ & Number of words enunciated in 2 min. & Verbal functions. \\
\hline Raven's progressive matrices test (Wechsler, 2000) & Number of matrices properly completed. & Non-verbal reasoning. \\
\hline
\end{tabular}

possible standardized form. In line with previous studies in the field, we focused on 6 cognitive domains (cf. Table 2).

We probed the verbal component of long-term memory using the delayed free recall of the 12 words from the Signoret BEM-144 (Signoret, 1991). (1) This test is taken from the French Batterie d'Efficience Mnésique, and requires participants to recall verbal information after a delay of approximately $7 \mathrm{~min}$. Long-term memory's visual component was assessed by combining the two versions of Baddeley's Doors test (Baddeley et al., 1994), and with the delayed recall of the Rey-Osterrieth complex figure (Rey, 1959). (2) These two tests asked, respectively, to recognize 12 previously encoded pictures of doors, and to redraw an abstract geometrical shape copied approximately $3 \mathrm{~min}$ earlier. They are both standardized tests of visual memory with good face validity and available normative data. Auditory-verbal short-term memory was evaluated using the size of the forward digit span (Godefroy et al., 2008) (3), which requires participants to immediately recall the highest number of digits in the order they were presented. This task is also part of the Wechsler Adult Intelligence ScaleThird Edition (WAIS-III; Wechsler, 2000). Processing speed was measured with the digit-symbol coding subtest of the WAIS-III (Wechsler, 2000), and with the number of items processed in the d2 test (Brickenkamp, 1981). (4) In these two tests, the subject is asked to associate or to discriminate visual stimuli as quickly as possible. The digit-symbol coding is part of the WAIS-III (Wechsler, 2000), and the $\mathrm{d} 2$ test is a valid measure of attention and processing speed based on German and American normative samples. The $\mathrm{d} 2$ is a time-restricted pencil-and-paper test that asks participants to cross out as many letter "d"s with two marks above or below them, in any order. The surrounding distractors are relatively similar to the target stimulus (a "p" with two marks or a "d" with one or three marks). We administered the non-verbal Raven's progressive matrices test (Wechsler, 2000) to estimate participants' non-verbal reasoning skills. This test is also a good proxy for Spearman's general intelligence (g) factor. (5) In this test, participants are presented with an unfinished matrix of drawings, and have to choose which of the proposed answers logically completes the matrix. Finally (6), phonemic and semantic verbal fluency tasks (Cardebat et al., 1990) were administered to assess participants' verbal functions.
These time-restricted tasks ask to recite as many words beginning with a given letter (phonemic) or belonging to a given semantic category (semantic) as possible. They are frequently used to assess cognition after neurological damage (Henry and Phillips, 2006). Performances on these tests can be improved by applying strategies (clustering by- and switching between-phonemic or semantic word categories).

\section{STATISTICAL ANALYSES}

All the statistical analyses were performed with STATISTICA software (StatSoft, 2011). STATISTICA (data analyses software), 10th version (www.statsoft.fr). The weakest significance threshold was set at $p=0.05$, uncorrected for multiple comparisons.

Two chi-square tests of independence were run to attest that the musician and non-musician groups did not differ significantly in gender frequencies. The first compared all four groups (middle-aged controls, middle-aged musicians, older controls, and older musicians), and the second tested the musician and non-musician groups, collapsed across age (cf. Table $\mathbf{1}$ ).

Two analyses of variance (ANOVAs) were conducted to attest that the four groups did not differ significantly on education and occupation level (cf. Table 1). For these variables, we also ran two $t$-tests, where the musician and non-musician groups were collapsed across age. Moreover, two-sample $t$-tests were run to confirm that there was no statistical difference in age between the middle-aged musicians and non-musicians, and the older musicians and non-musicians. Finally, twosample $t$-tests were run on the middle-aged and older musicians' age at training onset and frequency of training (cf. Table 1).

For informative purposes, a correlation analysis was performed between all the outcome measures (cognitive scores) of all the participants (cf. Table 3 ).

To seek for between-group differences regarding cognitive performances, we designed Two-Way ANOVAs specifying each cognitive score as the dependent variable, and age (middle-aged vs. older) and group (musicians vs. non-musicians) as independent factors. Each time, the Two-Way ANOVAs tested for the main effects of group and age, as well as for the Age*Group interaction effect (cf. Table 4). 
Table 3 | Pairwise correlations among the outcome measures (trend/significance $p$-values: ${ }^{\$} p<0.1 ;{ }^{*} p<0.05 ;{ }^{* *} p<0.01 ;{ }^{* * *} p<0.001$ ).

\begin{tabular}{|c|c|c|c|c|c|c|c|c|}
\hline & 8 & 9 & 7 & 6 & 5 & 4 & 3 & 2 \\
\hline & $\begin{array}{l}\text { Phonemic } \\
\text { fluency }\end{array}$ & $\begin{array}{l}\text { Semantic } \\
\text { fluency }\end{array}$ & d2 test & $\begin{array}{l}\text { Digit-symbol } \\
\text { coding }\end{array}$ & Raven's matrices & $\begin{array}{l}\text { Forward digit } \\
\text { span }\end{array}$ & $\begin{array}{l}\text { Rey-Osterrieth } \\
\text { complex figure }\end{array}$ & $\begin{array}{c}\text { Doors } \\
\text { test }\end{array}$ \\
\hline 1 & $0.43^{* * *}$ & $0.31^{*}$ & $0.22^{\$}$ & $0.37 * *$ & $0.14^{\mathrm{ns}}$ & $0.1^{\mathrm{ns}}$ & $0.18^{\mathrm{ns}}$ & $0.17^{\mathrm{ns}}$ \\
\hline 2 & $0.1^{\mathrm{ns}}$ & $0.05^{\mathrm{ns}}$ & $0.28 *$ & $0.16^{\mathrm{ns}}$ & $0.33^{* *}$ & $0.01^{\mathrm{ns}}$ & $0.38 * *$ & \\
\hline 3 & $0.16^{\mathrm{ns}}$ & $0.05^{\mathrm{ns}}$ & $0.35 * *$ & $0.44 * * *$ & $0.35^{* *}$ & $0.2^{\mathrm{ns}}$ & & \\
\hline 5 & $0.19^{n s}$ & $0.3^{*}$ & $0.31 *$ & $0.55^{* * *}$ & & & & \\
\hline 6 & $0.47 * * *$ & $0.31 *$ & $0.61 * * *$ & & & & & \\
\hline 7 & $0.26^{*}$ & $0.22^{\$}$ & & & & & & \\
\hline 9 & $0.48 * * *$ & & & & & & & \\
\hline
\end{tabular}

Squares featuring tests meant to measure the same cognitive domain are shaded.

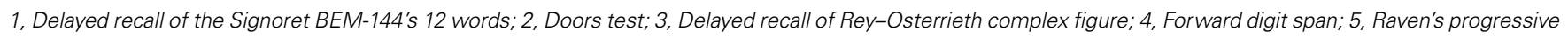
matrices; 6, Digit-symbol coding; 7, d2 test; 8, Phonemic fluency; 9, Semantic fluency.

Table 4 | Means (SDs) for neuropsychological Z scores, as well as $F$-values resulting from the Two-Way ANOVAs (trend/significance $p$-values: $\left.{ }^{\$} p<0.1 ;{ }^{*} p<0.05 ;{ }^{* *} p<0.01 ;{ }^{* * *} p<0.001\right)$.

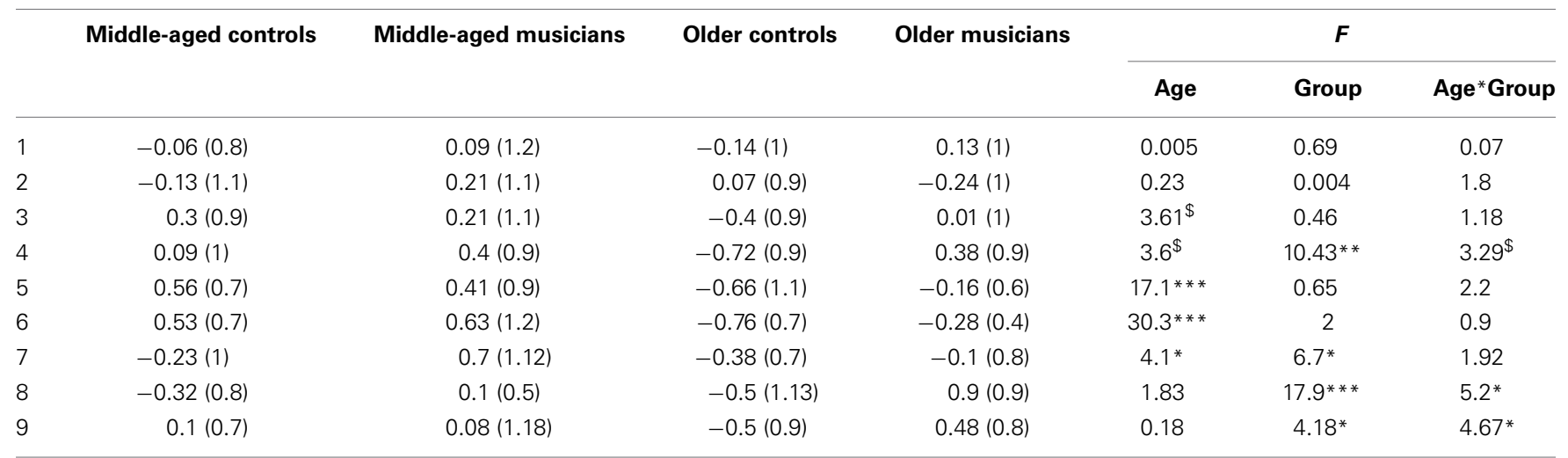

1, Delayed recall of the Signoret BEM-144's 12 words; 2, Doors test; 3, Delayed recall of Rey-Osterrieth complex figure; 4, Forward digit span; 5, Raven's progressive matrices; 6, Digit-symbol coding; 7, d2 test; 8, Phonemic fluency; 9, Semantic fluency.

\section{STUDY 1: RESULTS \\ DEMOGRAPHIC MATCHING}

The two chi-square tests of independence showed that the four groups did not differ on gender frequencies $\left[\chi_{(3, N=68)}^{2}=2.15\right.$, $p=0.54]$, and nor did the musician and non-musician groups collapsed across age, $\left[\chi_{(1, N=68)}^{2}=2.15, p=0.14\right]$.

No significant difference was revealed by the ANOVAs run on the mean years of education $\left[F_{(3,64)}=1.29, p=0.28\right]$, and professional occupation stimulating quality $\left[F_{(3,64)}=2.19, p=\right.$ 0.1 ). There was also no significant difference when comparing the musician and non-musician groups (collapsed across age) on professional occupations $\left[t_{(66)}=1.26, p=0.21\right]$, but the musicians tended to be more highly educated than the non-musicians $\left[t_{(66)}=1.76, p=0.08\right]$.

$T$-tests confirmed that there was no difference in age between musicians and non-musicians, be they middle-aged $\left[t_{(31)}=0.48\right.$, $p=0.63]$, or older $\left[t_{(33)}=-0.09, p=0.93\right]$.

Finally, $t$-tests comparing the middle-aged and older musicians on frequency of training $\left[t_{(32)}=1.71, p=0.1\right]$, and age at onset of practice $\left[t_{(32)}=-1.84, p=0.07\right]$, revealed trends toward significance, as the middle-aged musicians tended to have started musical training earlier and to have practiced more frequently than the older musicians $(p \leq 0.1)$.

\section{BETWEEN-GROUP DIFFERENCES IN THE AGE EFFECT ON COGNITION}

To explore whether musical practice interacted with the age effect, each cognitive score was entered in a Two-Way ANOVA, with group and age as explanatory variables (cf. Table 4).

\section{Verbal long-term memory}

The delayed recall of the 12 words taken from the BEM-144 yielded no main effect of either group, $\left[F_{(1,64)}=0.69, p=0.41\right]$, or age, $\left[F_{(1,64)}=0.005, p=0.94\right]$, and no interaction effect $\left[F_{(1,64)}=0.07, p=0.8\right]$.

\section{Visual long-term memory}

Performances on Baddeley's Doors test revealed no main effect of either group $\left[F_{(1,64)}=0.004, p=0.95\right]$; or age $\left[F_{(1,64)}=0.23\right.$, 
$p=0.63]$; and no Group*Age interaction effect $\left[F_{(1,64)}=1.83\right.$, $p=0.18]$. Regarding the delayed recall of the Rey-Osterrieth complex figure, results indicated no main effect of group $\left[F_{(1,64)}=0.46, p=0.5\right]$; a trend toward significance for the main effect of age $\left[F_{(1,64)}=3.6, p=0.06\right]$; and no interaction effect $\left[F_{(1,64)}=1.2, p=0.3\right]$.

\section{Auditory-verbal short-term memory}

The Two-Way ANOVA conducted on the auditory forward digit span scores revealed a main effect of group $\left[F_{(1,64)}=10.43\right.$, $p<0.01]$, and trends toward significance for the main effect of age $\left[F_{(1,64)}=3.55, p=0.06\right]$, and the interaction effect $\left[F_{(1,64)}=3.29, p=0.07\right]$.

\section{Non-verbal reasoning}

Raven's progressive matrices' scores revealed a significant main effect of age, $F_{(1,64)}=17.1, p<0.0001$, but no significant effect of group $\left[F_{(1,64)}=0.65, p=0.42\right]$, or the Group*Age interaction $\left[F_{(1,64)}=2.2, p=0.14\right]$.

\section{Processing speed}

Performances on the digit-symbol coding test showed no significant group effect $\left[F_{(1,64)}=1.98, p=0.16\right]$; a significant "age" effect $\left[F_{(1,64)}=30.3 ; p<0.001\right]$; and no significant interaction $\left[F_{(1,64)}=0.88, p=0.35\right]$.

Regarding the $\mathrm{d} 2$ test, analysis revealed significant effects of group, $\left[F_{(1,64)}=6.7, p<0.05\right]$, and age $\left[F_{(1,64)}=4.1\right.$, $p<0.05]$, but no significant interaction effect $\left[F_{(1,64)}=1.93\right.$, $p=0.17)$.

\section{Verbal fluencies}

The number of words provided during the phonemic fluency task showed a significant effect of group $\left[F_{(1,64)}=17.9\right.$, $p<0.001]$, no age effect $\left[F_{(1,64)}=1.83, p=0.18\right]$, and a significant interaction effect $\left[F_{(1,64)}=4, p<0.05\right]$.

Post hoc analysis showed that the middle-aged and older controls had very similar performances $(p=0.5)$, whereas the older musicians performed significantly better than the middle-aged musicians $(p<0.05)$. It resulted in a difference in performances between the older musicians and non-musicians $(p<0.001)$. The performances of the middle-aged musicians and non-musicians were the same ( $p=0.18$ ) (cf. Figure 2).

Regarding semantic fluency, the Two-Way ANOVA revealed a significant effect of group $\left[F_{(1,64)}=4.19, p<0.05\right]$, no effect of age $\left[F_{(1,64)}=0.18, p=0.67\right]$, and a significant interaction $\left[F_{(1,64)}=4.67, p<0.05\right]$.

Post-hoc analysis revealed that the older controls tended to perform worse than their middle-aged counterparts $(p=0.07)$, but there was no difference between the older and middle-aged musicians $(p=0.22)$. Again, there was a significant difference between older controls and older musicians $(p<0.01)$; and no difference between middle-aged controls and musicians $(p=0.93)$ (cf. Figure 2).

\section{STUDY 1: DISCUSSION}

In order to explore whether regular engagement in musical activities is associated with a decrease in the age effect on some cognitive functions, we studied the cognitive performances of middle-aged and older musicians in comparison with control participants. In line with the literature, results were as follows:

\section{NO MAIN EFFECT OF MUSICAL PRACTICE}

We found no musical practice-related difference on the verbal and visual modalities of long-term memory. Hanna-Pladdy and MacKay (2011) had previously found that musical engagement in older individuals was linked to better performances in visual memory. This finding was not replicated here, despite using a virtually identical test (delayed visual figure reproduction).

We also found that musical practice was not associated with better performances on Raven's progressive matrices, suggesting that there is no link between engagement in musical activities and non-verbal reasoning skills. Correlational studies regarding musical training and non-verbal reasoning skills (assessed using virtually similar tests) have sometimes reported positive findings (e.g., Forgeard et al., 2008; Bailey and Penhune, 2012), but not always (e.g., Franklin et al., 2008; Schellenberg and Moreno, 2009). The null finding of the present study adds to the uncertainty about the

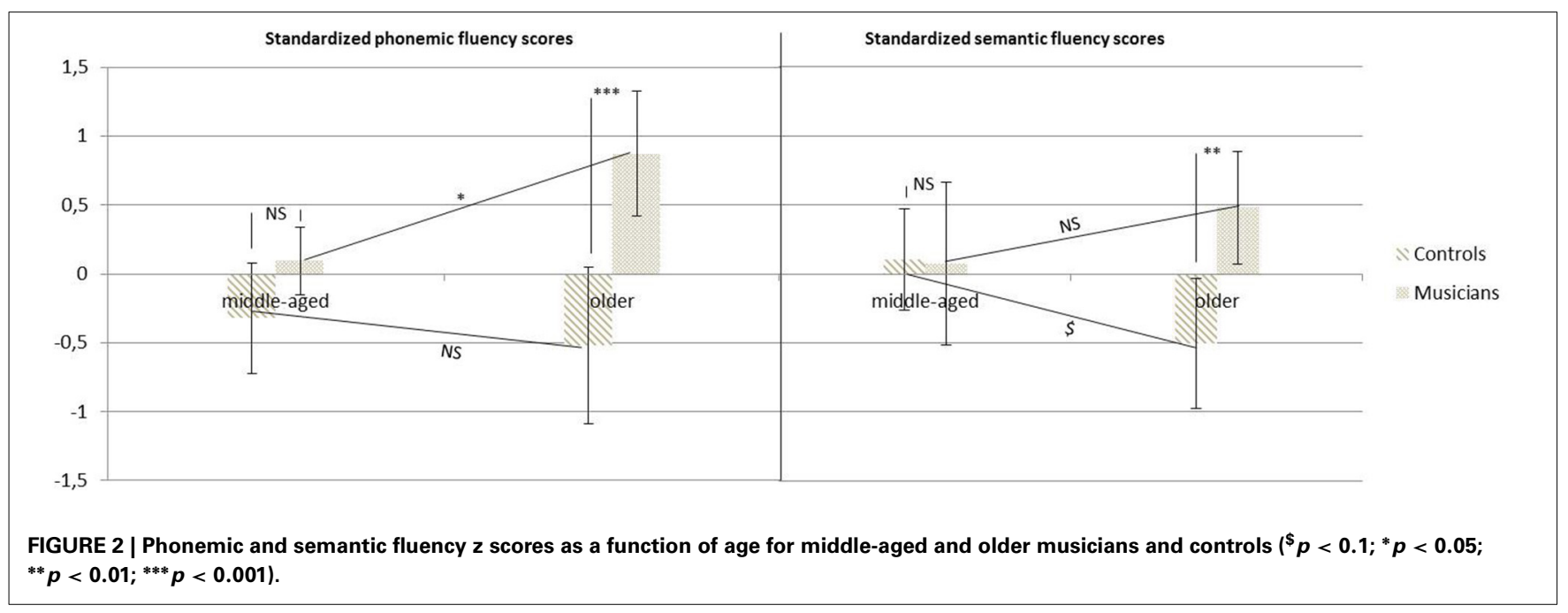


association between musical training and non-verbal reasoning skills.

In the same vein, digit-symbol coding was not performed better by musician participants of our sample. Individualized music lessons (learning to play the piano) given to 16 older nonmusicians were shown to increase performances on this measure (Bugos et al., 2007). Here, we found that older musicians who had been practicing music since childhood were no better at this test.

\section{AN EFFECT OF MUSICAL PRACTICE THAT DOES NOT INTERACT WITH AGE}

For processing speed, as assessed with the $\mathrm{d} 2$ test, we found significantly better performances for musician individuals compared with non-musicians, but differences between middle-aged and older participants were the same for both groups. The literature investigating musical practice during old age had already reported a trend toward significance for difference on the TMT A (HannaPladdy and MacKay, 2011). This finding was replicated here with a different test, and with the precision that age-related differences were the same for both musicians and non-musicians.

Regarding the size of the digit span, we found that musicians performed significantly better than their non-musician counterparts. This result goes against Hanna-Pladdy et al.'s two crosssectional studies $(2011,2012)$, which did not report such findings even though they used the same test. In addition, we showed a trend toward significance for the interaction with age, but which was not significant. That meant, again, that the age-related differences in performances were not significantly different between the groups.

These patterns of results did not match our first hypothesis, and were likely to reflect a predisposition in musicians for learning/practicing music, rather than a stimulation of learning/practicing music. Nevertheless, it is also conceivable that features of musical practice (e.g., score reading, typing, and auditory attention) lead to an increase in neural resources for processing speed and auditory-verbal short-term memory, endowing musicians with an advantage of a quantitative nature, with no further particular change.

\section{AN EFFECT OF MUSICAL PRACTICE THAT INTERACTS WITH AGE}

For the two verbal fluency tests (phonemic and semantic), results showed that musicians produced significantly more correct words than non-musicians. This was only partially in agreement with Hanna-Pladdy and Gajewski (2012), as they found the same effect for phonemic, but not semantic fluency. Therefore, we confirmed that older individuals who practice music score higher on a test measuring verbal skills.

In addition, significant interactions with age indicated that performances were relatively similar between middle-aged and older individuals of the control groups (with a trend toward reduced semantic fluency for older participants), but increased significantly in musicians for phonemic fluency.

The semantic and phonemic fluency tasks were therefore the only measures that confirmed our hypothesis of different agerelated changes for musicians compared with non-musicians. However, we did not find significant effect of age on these measures, making them less interesting in the framework of cognitive reserve. Moreover, it is important to point out that for these two tests, no difference was found between musicians and nonmusicians of the middle-age groups. This did not really suggest a transformative effect of musical practice, because in the case of an actual stimulation, one would have expected musicians to outperform non-musicians from middle age onwards.

\section{STUDY 2: MATERIALS AND METHODS STUDY 2: PARTICIPANTS}

In this second step, we sought for a link between the characteristics of the musicians' practice and their performances on tests having revealed significant interactions in Study 1 (i.e., phonemic and semantic fluencies). To probe the age at training onset effect, we added a sample of older musicians who had started music in adulthood (called "short-term musicians"), and compared their performances with those of the age-matched participants of Study 1 (the older "long-term musicians" and older controls). We also questioned the influence of a characteristic of current practice by running a correlation analysis between the older musicians' frequency of training and their performances.

Twelve older amateur musicians (mean age $=70.04$ years, $S D=7.7, \min =61, \max =83$ ) who had started music at a mean age of 42.7 years $(S D=11)$ were recruited from French conservatories or music schools. As for Study 1, no self-educated musicians were included, they had learned at least 2 new pieces during the last year, and they had an uninterrupted time of practice of at least 4 years at the time of the study (mean training duration $=$ 25.8 years, $S D=12.38, \min =6, \max =40)$, with at least 4 h' practicing a week (mean frequency $=8.08 \mathrm{~h}, S D=7.24$, $\min =$ $4, \max =30)($ cf. Table 5).

\section{STUDY 2: NEUROPSYCHOLOGICAL ASSESSMENT}

Study 2's neuropsychological battery was exactly the same as the one used in Study 1. It comprised the same tests and was administered in an identical way by the same experimenters. $Z$ score values were computed based on the entire Study 2's sample.

\section{STUDY 2: STATISTICAL ANALYSES}

A Chi-Square test of independence was run on the between-group gender frequencies to attest that the male/female ratios did not differ significantly. Three ANOVAs were conducted on the means for age, education, and occupation, to attest that the three groups of participants were similar on these measures.

To locate the short-term musician group's performances relative to the long-term musician and the control groups, we conducted ANOVAs on the cognitive scores having revealed interaction effects in Study 1 (i.e., the two verbal fluency tasks). Then, if the ANOVAs led to a significant effect of group, we ran post-hoc analyses (Least Square Deviation LSD) for pairwise comparisons.

Finally, to see whether the musicians' frequency of training explained their number of recalled words, we conducted a nonparametric correlation analysis (Spearman's rho) between these variables for all the musicians of the Study 2's sample.

\section{STUDY 2: RESULTS DEMOGRAPHIC MATCHING}

The chi-square test of independence showed no between-group difference for gender frequencies $\left[\chi_{(2, N=47)}^{2}=1.7, p=0.43\right]$. 
The One-Way ANOVAs ran on age $\left[F_{(2,44)}=1.3, p=0.28\right]$, education $\left[F_{(2,44)}=1.71, p=0.19\right]$ and occupation $\left[F_{(2,44)}=\right.$ $0.36, p=0.7]$, confirmed that the groups did not differ on these measures (cf. Table 5).

The two-sample $t$-tests comparing the practice characteristics of the two musician groups revealed significantly different ages at training onset $\left[t_{(25)}=-10.26, p<0.001\right]$, but similar training frequencies $\left[t_{(25)}=0.41, p=0.74\right]$ (cf. Table 5).

\section{BETWEEN-GROUP DIFFERENCES FOR PHONEMIC FLUENCY}

Phonemic fluency scores showed a significant main effect of group $\left(F_{(2,44)}=7.51, p<0.05\right)$. Post-hoc analysis revealed that the long-term musicians scored significantly higher than the short-term musicians $(p<0.05)$, the latter being no different from control participants ( $p=0.46$ ) (cf. Figure 3 ).

\section{BETWEEN-GROUP DIFFERENCES FOR SEMANTIC FLUENCY}

Semantic fluency scores revealed a significant effect of group $\left(F_{(2,44)}=6.43, p<0.01\right)$. Post-hoc analysis indicated that there was no difference in the performances of the two groups of musicians $(p=0.23)$, and that the short-term musician group also performed better than control participants $(p<0.05)$ (cf. Figure 3).

\section{CORRELATION ANALYSIS}

Results of the correlation analysis between the musicians' semantic and phonemic fluency scores and their frequency of training revealed no significant relation (cf. Table 6).

\section{STUDY 2: DISCUSSION}

To seek for a link between practice characteristics and older musicians' superior performances, we conducted a second study (Study 2), in which we included a sample of different older musicians (they had begun practicing music 30 years later on average than the musicians in Study 1). Results indicated that there was no link between frequency of training and verbal fluency performances. Moreover, because the two musician groups (long-term and short-term) had identical performances on the

Table 5 | Means (SDs) and inferential statistics for demographic data and practice characteristics of short-term and long-term musicians (trend/significance $p$-values: ${ }^{* *} p<0.001$ ).

\begin{tabular}{|c|c|c|c|c|c|}
\hline & Controls $(n=20)$ & Long-term musicians ( $n=15)$ & Short-term musicians $(n=12)$ & $F / \chi^{2}$ & $\boldsymbol{p}$ \\
\hline \multicolumn{6}{|l|}{ ANOVAs $/ \chi^{2}$} \\
\hline Sex ratio (M/F) & $7 / 13$ & $8 / 7$ & $7 / 14$ & 1.7 & 0.43 \\
\hline Education (years) & $13(2.5)$ & $14(2.5)$ & $14.6(3.6)$ & 1.7 & 0.19 \\
\hline Occupation & $3.1(1)$ & $3(0.5)$ & $3.2(1.1)$ & 0.4 & 0.7 \\
\hline \multicolumn{6}{|l|}{ TWO-SAMPLE $t$-TESTS } \\
\hline Training onset (age) & & $11.2(4.5)$ & $42.7(11)$ & -10.26 & $0.000 * * *$ \\
\hline Training frequency (h/week) & & $9.2(6.6)$ & $8.1(7.2)$ & 0.41 & 0.74 \\
\hline
\end{tabular}

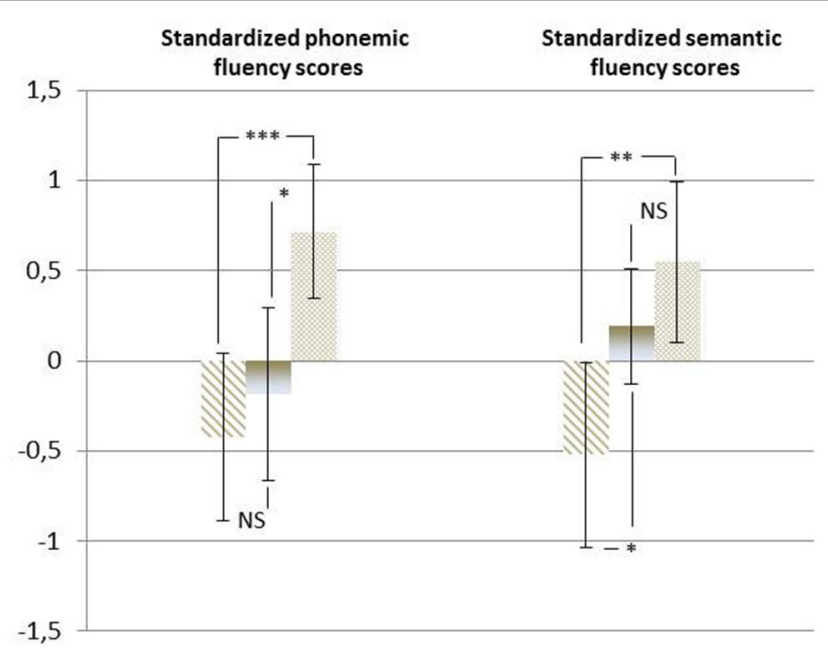

Older controls

- Older short-term musicians

Older long-term musicians

$\left({ }^{*} p<0.05 ;{ }^{* *} p<0.01 ;{ }^{* * *} p<0.001\right)$. 
Table 6 | Spearman's rank correlation coefficients between older musicians' frequency of training and their phonemic and semantic fluency scores.

\begin{tabular}{lcc}
\hline & Phonemic fluency & Semantic fluency \\
\hline Frequency of training (h/week) & $0.29(p=n s)$ & $0.19(p=n s)$ \\
\hline
\end{tabular}

semantic version, we concluded that the older musicians' better ability in this test was not explained by their practice, and probably constituted a confounding factor.

For phonemic fluency, results showed another pattern, indicating that musicians who had started their musical training during adulthood did not differ from controls. This could be in line with works showing that practice-related brain or cognitive differences are more pronounced when training starts at an early age (Elbert et al., 1995; Schlaug et al., 1995; Amunts et al., 1997; Steele et al., 2013). As verbal fluency assesses mainly verbal functions, our results also corroborated studies reporting better performances across a wide variety of language-related tests for children who have learned to play music (e.g., vocabulary; Forgeard et al., 2008; Moreno et al., 2009). In line with a previous investigation (Hanna-Pladdy and Gajewski, 2012), the present study showed that musical training in childhood is also associated with better literacy in old age, regardless of current musical engagement. The long-term influence of early environmental factors on brain and cognition has already been attested in animal studies (FernándezTeruel et al., 1997). Moreover, in humans, educational attainment is known to be a major factor in determining individuals' cognitive reserve later in life (Stern, 2012), even when occupation is controlled for. In the field of music, Gooding et al. (2013) found that the amount of musical engagement from childhood until adulthood explained older individuals' verbal fluency and long-term memory performances. Therefore, it could be that the cognitive advantage we observed in the older musicians was linked to the musical education they had received during the sensitive period of childhood. From this perspective, music lessons would act as an environmental enrichment which endows people who benefit it with better verbal skills in later life. Then again, given that our two studies had a cross-sectional design, our results may also indicate that individuals whose verbal skills are particularly good in old age are also those who were most likely to come to music early, and to continue their musical training lately.

\section{GENERAL DISCUSSION}

To sum up, our cognitive investigation of musicians yielded little evidence of reduced age-related changes owing to musical training. In line with this work's hypotheses, phonemic fluency was the only cognitive variable that potentially exemplified a positive usedependent effect in aging. Hanna-Pladdy and Gajewski (2012) had previously reported better phonemic fluency performances in older individuals who had practiced music in childhood, and the current status of training (active vs. inactive) was not linked with performances (Hanna-Pladdy and MacKay, 2011). This is in agreement with the absence of an association with frequency of training in the present study. In addition, we showed that the period at training onset seems to matter, as older musicians who had started musical practice in adulthood were no different from controls. This could be because there is a sensitive period for brain and cognitive plasticity (Penhune, 2011). The possibility that musical instruction in childhood could have a long-lasting influence on cognition in later life fits in with the definition of reserve, and the notion that "sensitive periods are epochs in development where specific experiences have enhanced and long-lasting effects on behavior and the brain" (Knudsen, 2004).

We found that only a verbal domain-related task fulfilled our criteria to be qualified as "stimulated by musical practice in aging." This could be viewed as an additional argument in favor of the existence of a special link between musical practice and verbal skills (Chan et al., 1998; Ho et al., 2003; Forgeard et al., 2008). Explanations for this presumed use-dependent enhancement of speech fluency include the processing of common auditory features in music and language (Patel and Iversen, 2007), and the strengthening of the auditory-motor neural coupling that serves both in music and in language production and perception (Bangert et al., 2006).

However, as already stated, phonemic fluency was not better performed by musicians compared with non-musicians for the middle-aged period of life. This is not really what we would expect in the case of actual stimulation. Moreover, in this work, many factors that are known to be associated with cognitive functioning and musical engagement were not controlled for, including the early sociocultural environment (family income, parental first language, parental education, etc.; Elpus, 2013). The first step of the present study investigated older people who had an ongoing musical training since childhood until late-life. Ecologically, such individuals are scarce, and they probably have particular personality traits that prompt them not only to play music, but also to engage in other behaviors that may help them to develop a cognitive reserve (healthy diet, moderate smoking/drinking, and other physical, social, and intellectual activities). Even more important, in this study, none of the IQ scores (verbal or performance) was assessed, but they are important determinants of individuals' cognitive reserve and the likelihood of their taking up music lessons (Schellenberg, 2011). Indeed, if music lessons do lead to improvements in IQ (Schellenberg, 2004), a comprehensive work has rigorously highlighted that children with a high IQ are more inclined than children with a lower IQ to attend music lessons (Schellenberg, 2011).

In the present study, a proxy for performance IQ (Raven's matrices test) showed no between-groups difference, but we found that the semantic fluency task was performed better by musicians, regardless the life period at training onset and the current frequency of training. This result could reflect a tendency of high verbal IQ people (or with a large vocabulary) to come up with — and pursue-music training later in life. However, only the musicians since childhood displayed better performances on phonemic fluency. Therefore, as in Hanna-Pladdy and Gajewski's study (2012), it could suggest that old musician individuals who started practicing music in their childhood display better verbal functions beyond what could be explained by their initially higher verbal IQ. 
To conclude, the quality of people's cognitive reserve depends on many intricate factors. It is highly conceivable that people who keep good cognitive functioning in old age are also those who are likely to pursue or expand their daily-life activities. In turn, maintaining these activities may certainly help to keep their cognition young. However, in our work $(N=79 / 5)$, which did not control for such selection bias-related confounding factors, we found that highly trained and active musicians (mean training duration $=38$ years; mean frequency of training $=10.86 \mathrm{~h} /$ week) did not perform any better than control participants on long-term memory (verbal and visual), non-verbal reasoning, and visual scanning (digit-symbol coding). For processing speed and auditory-verbal short-term memory, musicians scored higher but displayed no weaker age-related difference, thus ruling out a protective effect of practice (although both processing speed and auditory shortterm memory are highly solicited in musicians). Playing music, as speaking, are auditory-motor behaviors, and there are reports that some individuals own predisposing functional brain organization to learn faster in these abilities (Zatorre, 2013). It is therefore conceivable that some people keep disposing neural substrates that prompt them to pursue music later in life.

Only for phonemic fluency was musical practice associated with a different age-related change in performances, depending on the period at training onset (musicians who started in adulthood performed identically to controls). Therefore, according to us, this test was the solely potential candidate for a use-dependent adaptation interacting with musicians' cognitive aging.

Acquiring an expertise through deliberate practice leads to automation and to strategic processes that allow performances to be improved in a cost-effective way (neural efficiency; Kelly and Garavan, 2005). Other styles of behavior, such as exposure to novelty, may be more efficient in increasing old individuals' cognitive reserve.

\section{AUTHOR CONTRIBUTRIONS}

Baptiste Fauvel was actively involved in this study from design to drafting. He greatly contributed to participant recruitment and data acquisition. Finally, he conducted all the statistical analyses, produced the figures, participated in the interpretation of the results, and played a central role in revising the article in the wake of the reviewing process. Justine Mutlu made a substantial contribution to this study at every stage. Her assistance was particularly invaluable during revisions, when she participated in the supplementary statistical data analyses, the interpretation of the new results, the rational organization of the ideas, and the design of the figures. Moreover, she revised the manuscript many times in order to eliminate English grammatical mistakes and improve wording. At the outset, Eider M. Arenaza-Urquijo had provided invaluable ideas for interpreting the results. These ideas more or less vanished from the first version of the paper, but became central in the revised one. Moreover, she proved to be a huge help with the statistical data analyses. Finally, she was always generous with her advice, and shared many of her ideas during the revision process. Mathilde Groussard played an active part in this study from beginning to end. She helped in the design and the data acquisition coordination, and brought her theoretical knowledge to bear in the interpretation of the results. Finally, she revised the manuscript several times, allowing essential improvements to be made. As director of the laboratory, Francis Eustache ensured that we had all the material resources we needed to bring this study to a successful conclusion. His experience and knowledge in neuropsychology were essential for conceiving and designing the study, setting out the issues, and interpreting the results. Finally, he revised the manuscript, and provided relevant advice regarding the rational organization of the ideas. Béatrice Desgranges contributed her extensive experience to this study. Her knowledge in the field of cognitive aging proved essential to the study design, the interpretation of the results, and the drafting of the manuscript. Several of her ideas lie at the very core of the final version. Even more important, she highlighted several methodological problems-and how to solve them. Hervé Platel was the person behind this whole research project, and he coordinated the teamwork from start to finish. On many occasions during the design of the study and the interpretation of the results, his theoretical knowledge about music cognition saved us a huge amount of time. Moreover, his knowledge regarding the state of the art helped us to exploit the data in the most relevant way.

\section{ACKNOWLEDGMENTS}

This research was supported by a French Ministry of Research grant. We would like to thank Alice Rodaix, Isabelle Rameau, Elhia Demba, Manuella Boisset, and Camille Hou for their help in collecting data and their investment in this project. Many thanks, too, to Mona Leblond for helping with the English. Finally, this paper was substantially improved during reviewing, and we would like to address our gratitude to the two anonymous referees for their crucial help.

\section{REFERENCES}

Adam, S., Bonsang, E., Grotz, C., and Perelman, S. (2013). Occupational activity and cognitive reserve: implications in terms of prevention of cognitive aging and Alzheimer's disease. Clin. Interv. Aging 8, 377-390. doi: 10.2147/CIA. S39921

Amunts, K., Schlaug, G., Jäncke, L., Steinmetz, H., Schleicher, A., Dabringhaus, A., et al. (1997). Motor cortex and hand motor skills: structural compliance in the human brain. Hum. Brain Mapp. 5, 206-215.

Baddeley, A., Emslie, H., and Nimmo-Smith, I. (1994). Doors and People: a Test of Visual and Verbal Recall and Recognition. Bury St Edmunds: Thames Valley Test Company.

Bailey, J., and Penhune, V. B. (2012). A sensitive period for musical training: contributions of age of onset and cognitive abilities. Ann. N. Y. Acad. Sci. 1252, 163-170. doi: 10.1111/j.1749-6632.2011.06434.x

Bangert, M., Peschel, T., Schlaug, G., Rotte, M., Drescher, D., Hinrichs, H., et al. (2006). Shared networks for auditory and motor processing in professional pianists: evidence from fMRI conjunction. Neuroimage 30, 917-926. doi: 10.1016/j.neuroimage.2005.10.044

Brandler, S., and Rammsayer, T. H. (2003). Differences in mental abilities between musicians and non-musicians. Psychol. Music 31, 123-138. doi: $10.1177 / 0305735603031002290$

Brickenkamp, R. (1981). Test d2 Aufmerksamkeits Belastungs Test. Göttingen: Hogrefe.

Brochard, R., Dufour, A., and Després, O. (2004). Effect of musical expertise on visuospatial abilities: evidence form reaction times and mental imagery. Brain Cogn. 54, 103-109. doi: 10.1016/S0278-2626(03)00264-1

Bugos, J. A., Perlstein, W. M., McCrae, C. S., Brophy, T. S., and Bedenbaugh, P. H. (2007). Individualized piano instruction enhances executive functioning and working memory in older adults. Aging Ment. Health 11, 464-471. doi: $10.1080 / 13607860601086504$ 
Cardebat, D., Doyon, B., Puel, M., Goulet, P., and Joanette, Y. (1990). Formal and semantic lexical evocation in normal subjects. Performance and dynamics of production as a function of sex, age and educational level. Acta Neurol. Belg. 90, 207-217.

Chan, A. S., Ho, Y. C., and Cheung, M. C. (1998). Music training improves verbal memory. Nature 396, 128. doi: 10.1038/24075

Christensen, H., and Mackinnon, A. (1993). The association between mental, social and physical activity and cognitive performance in young and old subjects. Age Ageing 22, 175-182. doi: 10.1093/ageing/22.3.175

Dawson, W. J. (2014). Benefits of music training are widespread and lifelong: a bibliographic review of their non-musical effects. Med. Probl. Perform. Art. 29, 57-63.

Draganski, B., and May, A. (2008). Training-induced structural changes in the adult human brain. Behav. Brain Res. 192, 137-142. doi: 10.1016/j.bbr.2008. 02.015

Elbert, T., Pantev, C., Wienbruch, C., Rockstroh, B., and Taub, E. (1995). Increased cortical representation of the fingers of the left hand in string players. Science 270, 305-307. doi: 10.1126/science.270.5234.305

Elpus, K. (2013). Is it the music or is it selection bias? A nationwide analysis of music and non-music students' SAT scores. J. Res. Music Educ. 61, 175-194. doi: 10.1177/0022429413485601

Evans, D. A., Beckett, L. A., Albert, M. S., Hebert, L. E., Scherr, P. A., Funkenstein, H. H., et al. (1993). Level of education and change in cognitive function in a community population of older persons. Ann. Epidemiol. 3, 71-77. doi: 10.1016/1047-2797(93)90012-S

Fauvel, B., Groussard, M., Eustache, F., Desgranges, B., and Platel, H. (2013). Neural implementation of musical expertise and cognitive transfers: could they be promising in the framework of normal cognitive aging? Front. Hum. Neurosci. 7:693. doi: 10.3389/fnhum.2013.00693

Fernández-Teruel, A., Escorihuela, R. M., Castellano, B., González, B., and Tobeña, A. (1997). Neonatal handling and environmental enrichment effects on emotionality, novelty/reward seeking, and age-related cognitive and hippocampal impairments: focus on the Roman rat lines. Behav. Genet. 27, $513-526$.

Forgeard, M., Winner, E., Norton, A., and Schlaug, G. (2008). Practicing a musical instrument in childhood is associated with enhanced verbal ability and nonverbal reasoning. PLOS ONE 3:e3566. doi: 10.1371/journal.pone. 0003566

Foubert-Samier, A., Catheline, G., Amieva, H., Dilharreguy, B., Helmer, C., Allard, M., et al. (2010). Education, occupation, leisure activities, and brain reserve: a population-based study. Neurobiol. Aging 33, 423. doi: 10.1016/j.neurobiolaging.2010.09.023

Franklin, M. S., Rattray, K., Sledge Moore, K., Moher, J., Yip, C.-Y., and Jonides, J. (2008). The effect of musical training on verbal memory. Psychol. Music 36, 353-366. doi: 10.1177/0305735607086044

Godefroy, O., and Groupe de Réflexion sur l'Evaluation des Fonctions Exécutives. (2008). Fonctions Exécutives et Pathologies Neurologiques et Psychiatriques. Marseilles: Solal.

Gooding, L. F., Abner, E. L., Jicha, G. A., Kryscio, R. J., and Schmitt, F. A. (2013). Musical training and late-life cognition. Am. J. Alzheimers Dis. Other Demen. 29, 333-343. doi: 10.1177/1533317513517048

Green, C. S., and Bavelier, D. (2008). Exercising your brain: a review of human brain plasticity and training-induced learning. Psychol. Aging 23, 692-701. doi: 10.1037/a0014345

Hanna-Pladdy, B., and Gajewski, B. (2012). Recent and past musical activity predicts cognitive aging variability: direct comparison with general lifestyle activities. Front. Hum. Neurosci. 6:198. doi: 10.3389/fnhum.2012. 00198

Hanna-Pladdy, B., and MacKay, A. (2011). The relation between instrumental musical activity and cognitive aging. Neuropsychology 25, 378-386. doi: 10.1037/a0021895

Hannon, E. E., and Trainor, L. J. (2007). Music acquisition: effects of enculturation and formal training on development. Trends Cogn. Sci. 11, 466-472. doi: 10.1016/j.tics.2007.08.008

Hedden, T., and Gabrieli, J. D. (2004). Insights into the ageing mind: a view from cognitive neuroscience. Nat. Rev. Neurosci. 5, 87-96. doi: 10.1038/ nrn 1323

Henry, J. D., and Phillips, L. H. (2006). Covariates of production and perseveration on tests of phonemic, semantic and alternating fluency in normal aging. Neuropsychol. Dev. Cogn. B Aging Neuropsychol. Cogn. 13, 529-551. doi: $10.1080 / 138255890969537$

Ho, Y. C., Cheung, M. C., and Chan, A. S. (2003). Music training improves verbal but not visual memory: cross-sectional and longitudinal explorations in children. Neuropsychology 17, 439-450. doi: 10.1037/0894-4105.17.3.439

Hultsch, D. F., Hertzog, C., Small, B. J., and Dixon, R. A. (1999). Use it or lose it: engaged lifestyle as a buffer of cognitive decline in aging? Psychol. Aging 14, 245-263. doi: 10.1037/0882-7974.14.2.245

Huntsinger, S. C., and Jose, E. P. (1991). A test of Gardner's modularity theory: a comparison of short-term memory for digits and tones. Psychomusicology 10, 3-18. doi: 10.1037/h0094145

Jakobson, L. S., Lewycky, S. T., Kilgour, A. R., and Stoesz, B. M. (2008). Memory for verbal and visual material in highly trained musicians. Music Percept. 26, 41-55. doi: 10.1525/mp.2008.26.1.41

Kalpouzos, G., Chételat, G., Baron, J. C., Landeau, B., Mevel, K., Godeau, C., et al. (2009). Voxel-based mapping of brain gray matter volume and glucose metabolism profiles in normal aging. Neurobiol. Aging 30, 112-124. doi: 10.1016/j.neurobiolaging.2007.05.019

Kelly, A. M., and Garavan, H. (2005). Human functional neuroimaging of brain changes associated with practice. Cereb. Cortex 15, 1089-1102. doi: 10.1093/cercor/bhi005

Knudsen, E. I. (2004). Sensitive periods in the development of the brain and behaviour. J. Cogn. Neurosci. 16, 1412-1425. doi: 10.1162/0898929042304796

Mehr, S. A., Schachner, A., Katz, R. C., and Spelke, E. S. (2013). Two randomized trials provide no consistent evidence for nonmusical cognitive benefits of brief preschool music enrichment. PLoS ONE 8:e82007. doi: 10.1371/journal.pone.0082007

Moreno, S., Marques, C., Santos, A., Castro, S. L., and Besson, M. (2009). Musical training influences linguistic abilities in 8-year-old children: more evidence for brain plasticity. Cereb. Cortex 19, 712-723. doi: 10.1093/cercor/bhn120

Park, D. C., Lautenschlager, G., Hedden, T., Davidson, N. S., Smith, A. D., and Smith, P. K. (2002). Models of visuospatial and verbal memory across the adult life span. Psychol. Aging 17, 299-320. doi: 10.1037/0882-7974.17.2.299

Patel, A. D., and Iversen, J. R. (2007). The linguistic benefits of musical abilities. Trends Cogn. Sci. 11, 369-372. doi: 10.1016/j.tics.2007.08.003

Penhune, V. B. (2011). Sensitive periods in human development: evidence from musical training. Cortex 47, 1126-1137. doi: 10.1016/j.cortex.2011.05.010

Rey, A. (1959). Manuel de la Figure Complexe de Rey. Paris: Editions du Centre de Psychologie Appliquée.

Salthouse, T. A. (2010). Selective review of cognitive aging. J. Int. Neuropsychol. Soc. 16, 754-760. doi: 10.1017/S1355617710000706

Schellenberg, E. G. (2004). Music lessons enhance IQ. Psychol. Sci. 15, 511-514. doi: 10.1111/j.0956-7976.2004.00711.x

Schellenberg, E. G. (2011). Examining the association between music lessons and intelligence. Br. J. Psychol. 102, 283-302. doi: 10.1111/j.2044-8295.2010. 02000.x

Schellenberg, E. G., and Moreno, S. (2009). Music lessons, pitch processing, and g. Psychol. Music 38, 209-221. doi: 10.1177/0305735609339473

Schellenberg, E. G., and Peretz, I. (2008). Music, language and cognition: unresolved issues. Trends Cogn. Sci. 12, 45-46. doi: 10.1016/j.tics.2007. 11.005

Schlaug, G., Jäncke, L., Huang, Y., and Steimetz, H. (1995). In vivo evidence of structural brain asymmetry in musicians. Science 267, 699-701. doi: 10.1126/science.7839149

Schooler, C., and Mulatu, M. S. (2001). The reciprocal effects of leisure time activities and intellectual functioning in older people: a longitudinal analysis. Psychol. Aging 16, 466-482. doi: 10.1037/0882-7974.16.3.466

Signoret, J. (1991). Batterie d'Efficience Mnésique. Paris: Elsevier.

Steele, C. J., Bailey, J. A., Zatorre, R. J., and Penhune, V. B. (2013). Early musical training and white-matter plasticity in the corpus callosum: evidence for a sensitive period. J. Neurosci. 33, 1282-1290. doi: 10.1523/JNEUROSCI.357812.2013

Stern, Y. (2012). Cognitive reserve in ageing and Alzheimer's disease. Lancet Neurol. 11, 1006-1012. doi: 10.1016/S1474-4422(12)70191-6

Tierney, A. T., Bergeson-Dana, T. R., and Pisoni, D. B. (2008). Effects of early musical experience on auditory sequence memory. Empir. Musicol. Rev. 3, $178-186$.

Wang, H. X., Xu, W., and Pei, J. J. (2012). Leisure activities, cognition and dementia. Biochim. Biophys. Acta 1822, 482-491. doi: 10.1016/j.bbadis.2011.09.002 
Wechsler, D. (2000). Manuel de l'Échelle d'Intelligence de Wechsler Pour Adultes 3Ème Édition. Paris: Editions du Centre de Psychologie Appliquée.

Wilson, R. S., Barnes, L. L., Krueger, K. R., Hoganson, G., Bienias, J. L., and Bennett, D. A. (2005). Early and late life cognitive activity and cognitive systems in old age. J. Int. Neuropsychol. Soc. 11, 400-407. doi: 10.1017/S135561770 5050459

Zatorre, R. J. (2013). Predispositions and plasticity in music and speech learning: neural correlates and implications. Science 342, 585-589. doi: 10.1126/science.1238414

Conflict of Interest Statement: The authors declare that the research was conducted in the absence of any commercial or financial relationships that could be construed as a potential conflict of interest.
Received: 25 June 2014; accepted: 08 August 2014; published online: 09 October 2014. Citation: Fauvel B, Groussard M, Mutlu J, Arenaza-Urquijo EM, Eustache F Desgranges B and Platel H (2014) Musical practice and cognitive aging: two crosssectional studies point to phonemic fluency as a potential candidate for a usedependent adaptation. Front. Aging Neurosci. 6:227. doi: 10.3389/fnagi.2014.00227 This article was submitted to the journal Frontiers in Aging Neuroscience.

Copyright $\odot 2014$ Fauvel, Groussard, Mutlu, Arenaza-Urquijo, Eustache, Desgranges and Platel. This is an open-access article distributed under the terms of the Creative Commons Attribution License (CC BY). The use, distribution or reproduction in other forums is permitted, provided the original author(s) or licensor are credited and that the original publication in this journal is cited, in accordance with accepted academic practice. No use, distribution or reproduction is permitted which does not comply with these terms. 